\title{
High yield total syntheses of XH-14 derivatives using Sonogashira coupling reaction
}

\author{
Hyun Bae Bang, Su Young Han, Da Hye Choi, Jung Woon Hwang, and \\ Jong-Gab Jun* \\ Department of Chemistry and Institute of Natural Medicine, \\ Hallym University, Chuncheon 200-702, Korea \\ E-mail:jgjun@hallym.ac.kr
}

\begin{abstract}
A high yielding synthetic route to $\mathrm{XH}-14$ derivatives is described using a Sonogashira reaction as a key step. Introduction of iodine into the structure and optimization of the synthetic sequence were essential for the successful syntheses of $\mathrm{XH}-14$ derivatives. The nine-step reaction sequence gave 2 and 3 in 30\% and 55\% overall yields, respectively.
\end{abstract}

Keywords: XH-14, benzo[b]furan, Colvin rearrangement, Sonogashira coupling, iodocyclization.

\section{Introduction}

$\mathrm{XH}-14$ is known as a potent ingredient isolated from the root of Salvia miltiorrhiza Bunge (Chinese name 'Danshen'). Aqueous extracts of the root have been used widely in China for the treatment of cardiovascular diseases such as acute myocardiac infarction and angina pectoris. ${ }^{1}$ It was the first reported non-nucleoside-type potent adenosine $\mathrm{A}_{1}$ agonist and showed a high potency $\left(\mathrm{IC}_{50}=17 \mathrm{nM}\right)$ in the bovine adenosine $\mathrm{A}_{1}$ radioligand binding assay. ${ }^{2}$ Chemically pure XH-14 (1 mg/kg) was isolated from the dried root of Danshen and structurally identified as a benzo $[b]$ furan lignan. ${ }^{3}$ Many biologically active benzo[b]furan compounds are found in nature. ${ }^{4}$ The limited supply of XH-14 has prevented the diverse characterization of its biological activities. Several syntheses of $\mathrm{XH}-14$ and its derivatives have been reported including Sonogashira coupling methodology. ${ }^{5}$ However, emphasis was given only to the synthesis of C-2 and C-3 substituted analogs. Due to its high selectivity for the $\mathrm{A}_{1}$ receptor subtype, the preparation of analogs for SAR tests was clearly of interest. ${ }^{6}$ In order to prove the role of other substituents on XH-14 in biological selectivity, the modifications on benzofuran benzene unit were required. We report herein the convenient total syntheses of 6-methoxy- (2) and 5- 
methoxy-XH-14 (3) derivatives in nine steps from 2,4- and 2,5-dimethoxybenzaldehyde respectively (Figure 1).

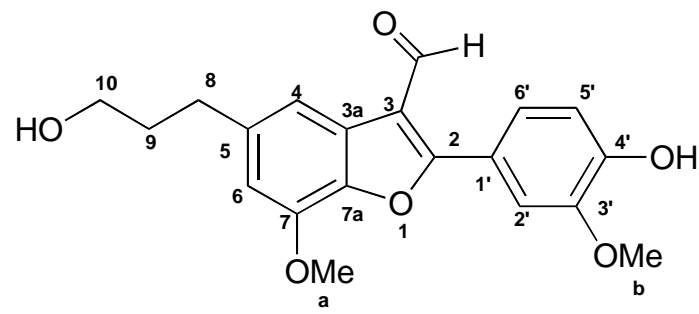

1

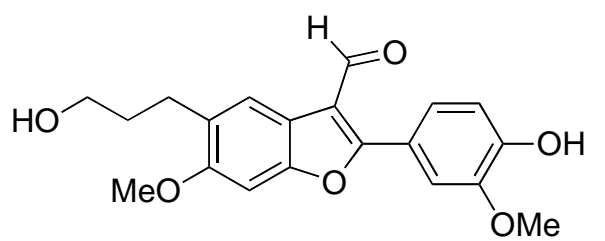

2

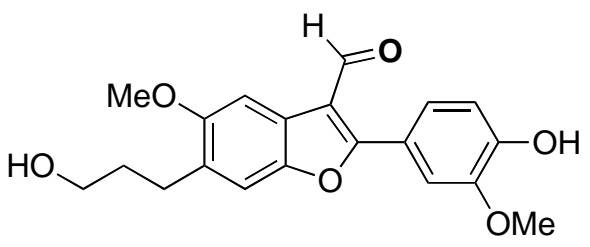

3

Figure 1. Structures of XH-14 (1), 6-methoxy- (2) and 5-methoxy-XH-14 (3) derivatives.

\section{Results and Discussion}

In the present work, a key feature is the introduction of iodine into the dimethoxy compounds 8 and 18 as well as the optimization of the reaction sequence. The Wittig reaction of 2,4dimethoxybenzaldehyde (4) with (carbethoxymethylene)triphenylphosphorane in methylene chloride under reflux produced conjugated ester $5(E: Z=19: 1)$ in $99 \%$ yield which was then reduced to 6 by hydrogenation (Scheme 1). Reduction of ester 6 with $\mathrm{LiAlH}_{4}$ yielded alcohol 7 in $98 \%$ yield which was then benzylated to give 8 in $86 \%$ yield. The regioselective halogenation of 8 was essential for the Sonogashira reaction to give the desired product 10. ${ }^{7}$ Fortunately, the desired 5-position where the halogen needs to be introduced is ortho and para to both methoxy groups; hence, 5-bromo compound 9a $(\mathrm{X}=\mathrm{Br})$ was easily obtained using Chern's method. ${ }^{\text {5e }}$ However, the bromobenzene 9a did not react in Sonogashira coupling with acetylene 10. ${ }^{8}$ The introduction of iodine was achieved using $\mathrm{I}_{2} / \mathrm{Ag}_{2} \mathrm{SO}_{4}$ in $\mathrm{EtOH}$ to give $9 \mathbf{b}$ in $88 \%$ yield. The earlier introduction of iodine in the reaction sequence (as shown in Scheme 2) was found to be unsuccessful. 


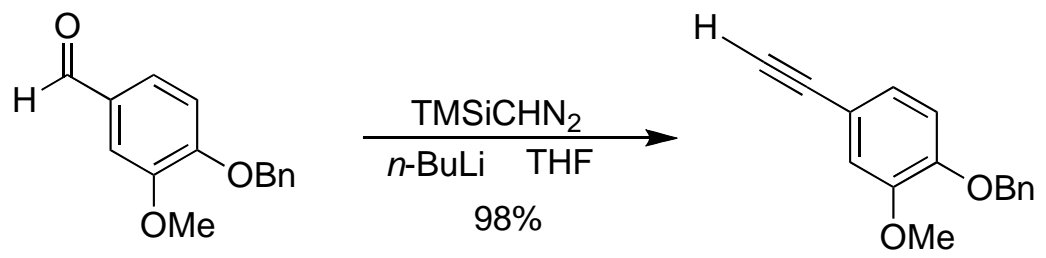

10

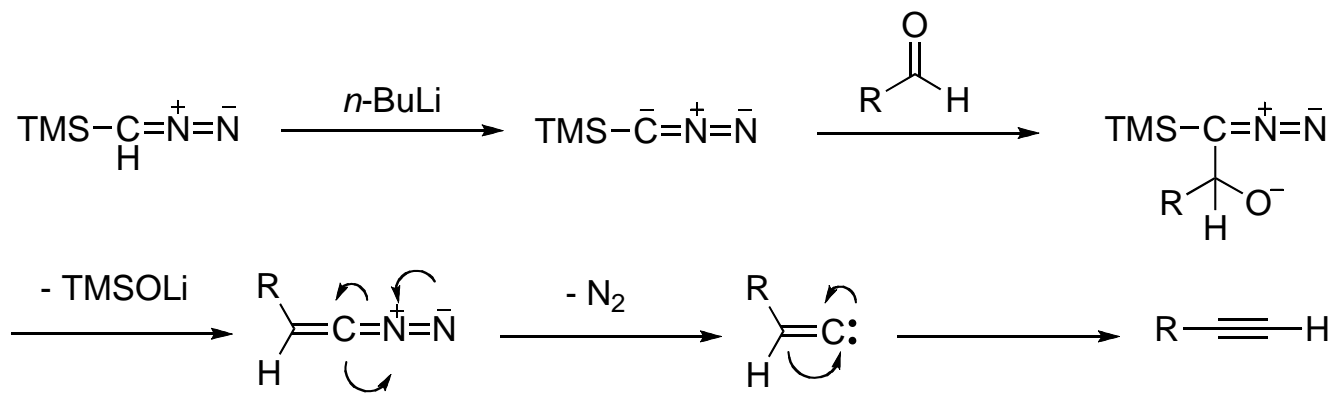

Figure 2. Colvin rearrangement of benzylated vanillin and reaction mechanism.

Compound 11 was obtained via conventional Sonogashira coupling ${ }^{10}$ of iodobenzene $\mathbf{9 b}$ with acetylene 10, which was easily prepared from benzylated vanillin with trimethylsilyldiazomethane by Colvin rearrangement ${ }^{9}$ (as shown in Figure 2). Iodine-induced

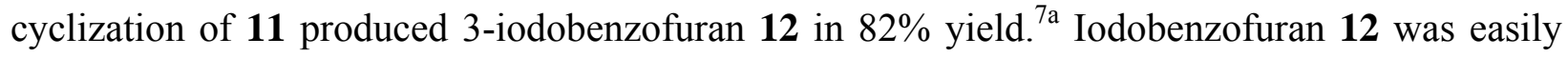
converted into formyl-benzofuran 13 by reaction with $t$-BuLi then $N$-formylpiperidine in toluene (74\%). Finally, careful debenzylation of 13 by $\mathrm{BBr}_{3}$ at $-78{ }^{\circ} \mathrm{C}$ gave 2-(4-hydroxy-3methoxyphenyl)-5-(3-hydroxypropyl)-6methoxybenzofuran-3-carbaldehyde (2) in 74\% yield. ${ }^{\text {e }}$ 

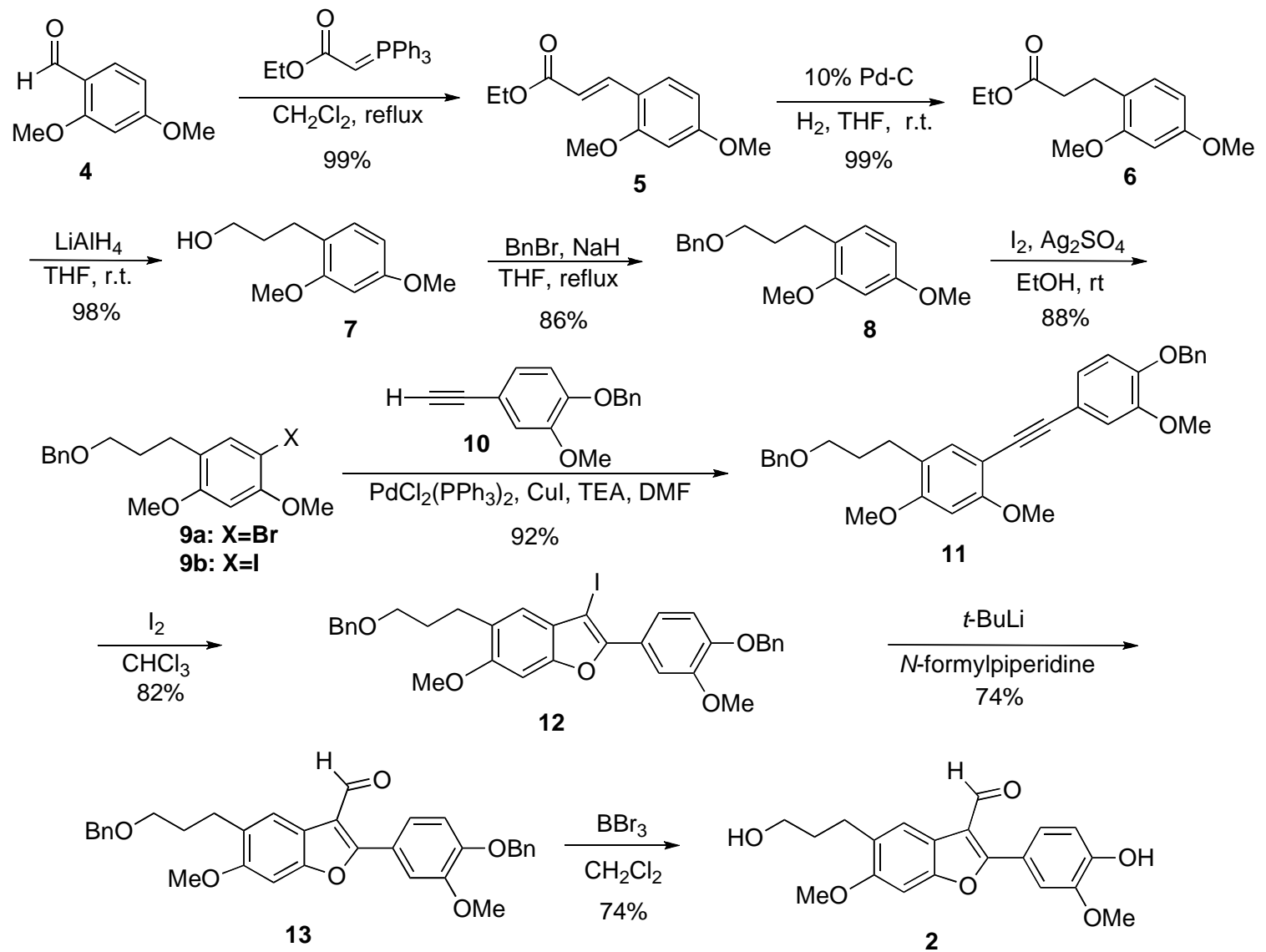

Scheme 1. Synthesis of 6-methoxy-XH-14 from 2,4-dimethoxybenzaldehyde.

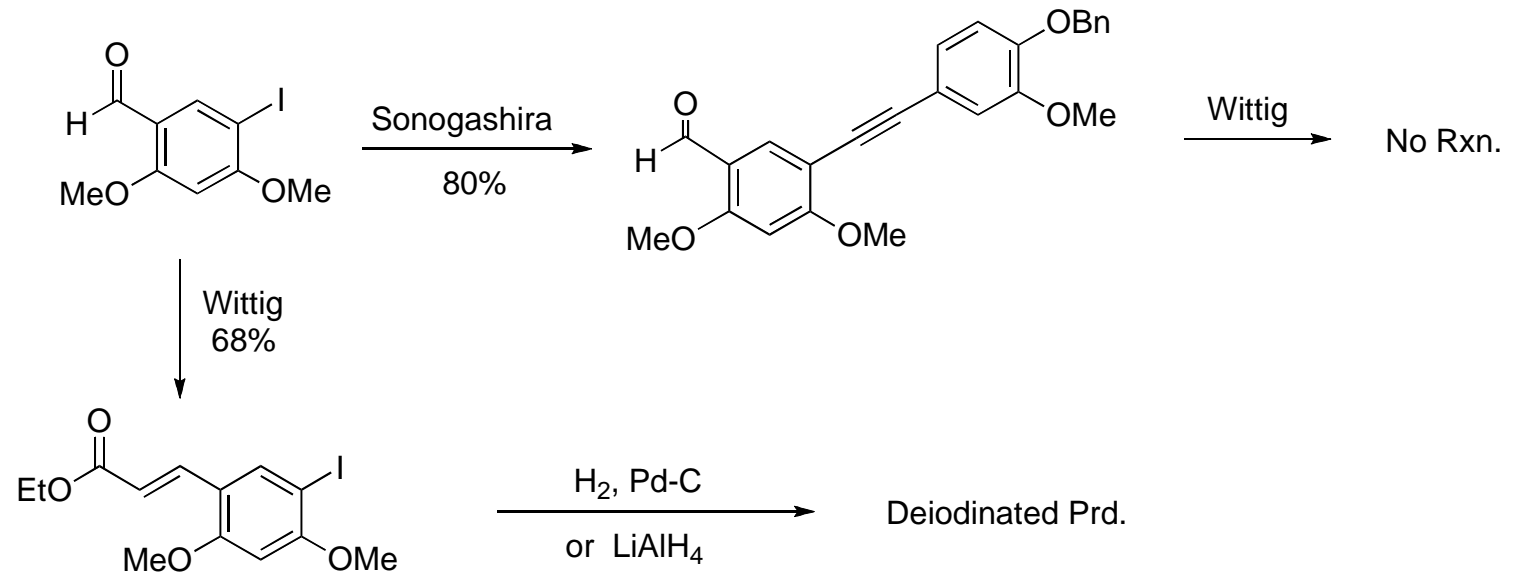

Scheme 2. Results of different reaction sequences.

5-Methoxy-XH-14 derivative (3) was easily prepared from 2,5-dimethoxybenzaldehyde (14) in nine steps using the same procedure as for 6-methoxy-XH-14 (Scheme 3). The Wittig reaction of 14 produced a $99 \%$ yield of conjugated ester 15 (E:Z=24:1) which was then converted to ester 
16 by hydrogenation in $96 \%$ yield. Reduction of 16 with $\mathrm{LiAlH}_{4}$ yielded alcohol $\mathbf{1 7}$ followed by benzylation gave 18 in $99 \%$ yield. The regioselective iodination of 18 with $\mathrm{I}_{2} / \mathrm{Ag}_{2} \mathrm{SO}_{4}$ in $\mathrm{EtOH}$ gave a 97\% yield of iodobenzene 19 then Sonogashira coupling gave 20 in 93\% yield. Iodineinduced cyclization of $\mathbf{2 0}$ produced 3-iodobenzofuran 21 in $82 \%$ yield, which was easily converted into formylbenzofuran 22 by reaction with $n$-BuLi then $N$-formylpiperidine (87\%). Finally, careful debenzylation of 22 by $\mathrm{BBr}_{3}$ gave 2-(4-hydroxy-3-methoxyphenyl)-6-(3hydroxypropyl)-5-methoxybenzofuran-3-carbaldehyde (3) in $92 \%$ yield.

The ${ }^{1} \mathrm{H}-\mathrm{NMR}$ chemical shifts for the aromatic protons of XH-14 derivatives (1-3) enabled easy differentiation the various structural possibilities (Figure 3). The $\mathrm{H}-4$ chemical shift of $\mathrm{XH}-$ 14 at $\delta 7.50(\mathrm{~d}, J=1.2 \mathrm{~Hz})$ was compared to the $\mathrm{H}-4$ chemical shifts of 6-methoxy (2) at $\delta 7.88(\mathrm{~s})$ and 5-methoxy (3) at $\delta 7.32(\mathrm{~s})$, and the H-6 chemical shift of XH-14 at $\delta 6.79(\mathrm{~d}, J=1.2 \mathrm{~Hz})$ was compared to the H-7 chemical shifts of 6-methoxy (2) at $\delta 7.18$ (s) and 5-methoxy (3) at $\delta 7.58$ (s).
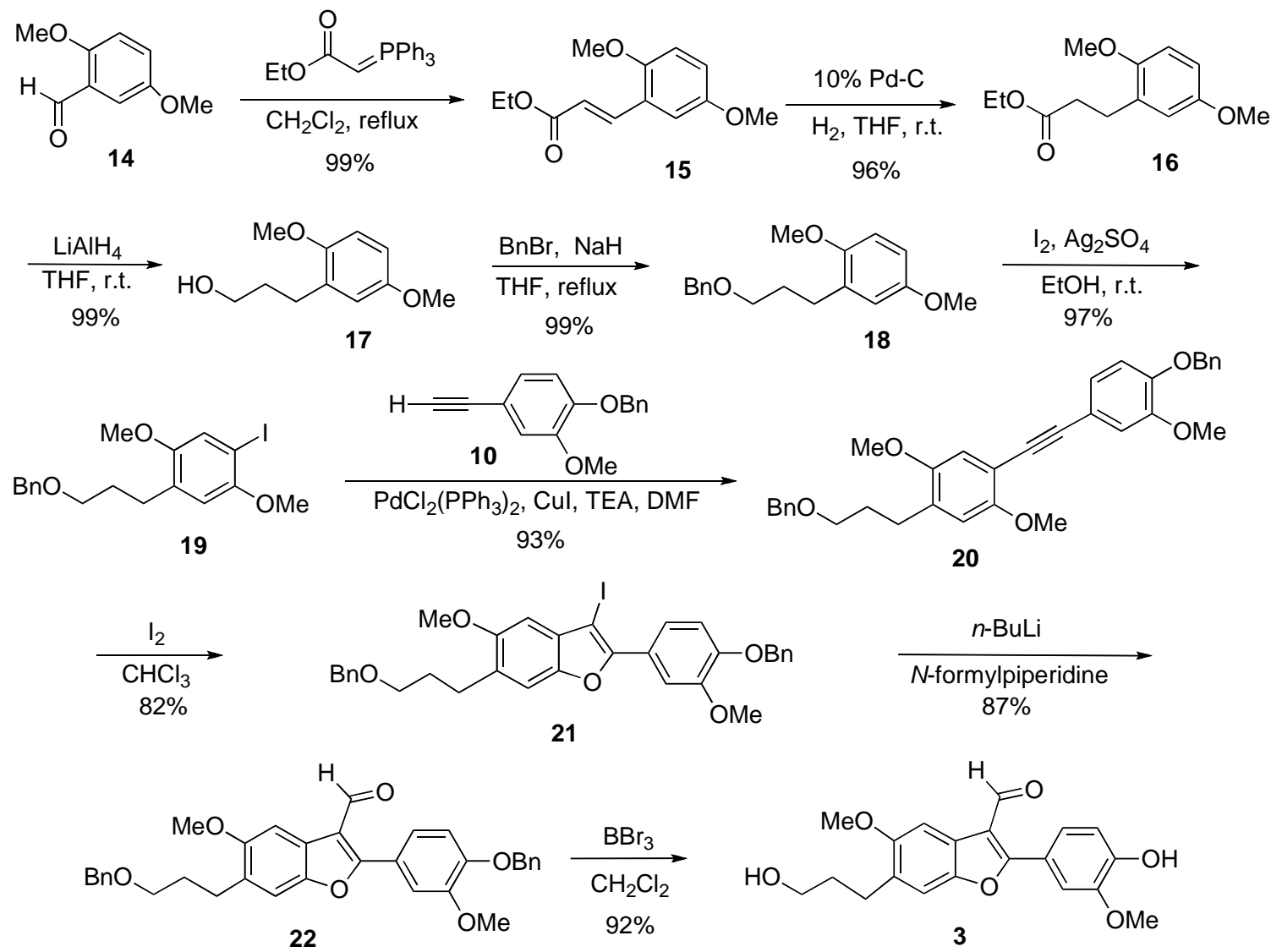

Scheme 3. Synthesis of 5-methoxy-apo-XH-14 from 2,5-dimethoxybenzaldehyde. 

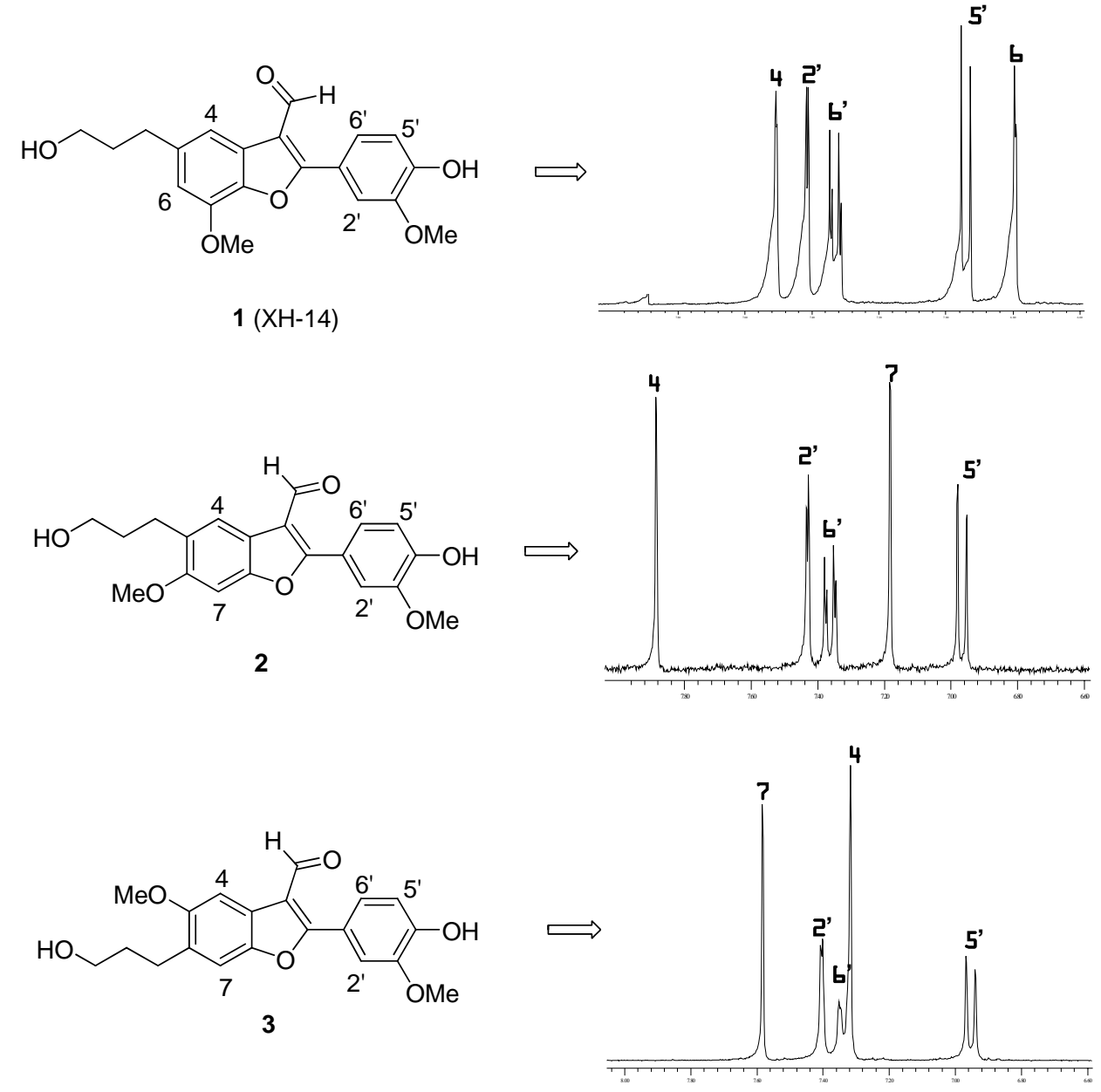

Figure 3. Comparison of ${ }^{1} \mathrm{H}$ NMR chemical shifts for aromatic protons of $\mathrm{XH}-14$ and derivatives.

\section{Conclusions}

In conclusion, nine-step sequences produced 6-methoxy-XH-14 (2) and 5-methoxy-XH-14 (3) in $30 \%$ and $55 \%$ overall yields respectively. These compounds are now under investigation for their biological activities compared to $\mathrm{XH}-14$.

\section{Experimental Section}

General Procedures. All chemicals used were purchased from commercial sources and used as received unless otherwise stated. NMR spectra were recorded on a Varian Mercury-300 MHz FTNMR for ${ }^{1} \mathrm{H}$ and $75 \mathrm{MHz}$ for ${ }^{13} \mathrm{C}$, with the chemical shifts $(\delta)$ reported in parts per million (ppm) 
relative to TMS and the coupling constants $(J)$ quoted in $\mathrm{Hz}$. $\mathrm{CDCl}_{3}$ was used as a solvent and an internal standard. Flash chromatography was carried out using silica gel Merck 60 (230-400 mesh). Thin-layer chromatography (TLC) was performed on DC-Plastikfolien 60, $\mathrm{F}_{254}$ (Merck, layer thickness $0.2 \mathrm{~mm}$ ) plastic-backed silica gel plates with visualization by UV light $(254 \mathrm{~nm})$ or by treatment with $p$-anisaldehyde. Melting points were measured on a MEL-TEMP II apparatus and are uncorrected.

1-(2-Carbethoxyethenyl)-2,4-dimethoxybenzene (5). To a solution of 2,4dimethoxybenzaldehyde (4) $(1.00 \mathrm{~g}, 6.02 \mathrm{mmol})$ in $\mathrm{CH}_{2} \mathrm{Cl}_{2}(100 \mathrm{~mL})$ was added (carbethoxymethylene)triphenylphosphorane $(3.31 \mathrm{~g}, 9.03 \mathrm{mmol}$ ) and the mixture was refluxed for 3 days. Solvent was removed by evaporation and the organic phase was extracted with $\mathrm{CH}_{2} \mathrm{Cl}_{2}$, washed with brine, dried and concentrated to give a crude solid. The solid was purified by chromatography (EtOAc:hexane $=1: 4)$ to give the pure product as a white solid $5(99 \%$, $E: Z=19: 1) . \boldsymbol{E}-5: \mathrm{R}_{f} 0.53$ (EtOAc:hexane=1:3); $\mathrm{mp} \mathrm{50-52}{ }^{\circ} \mathrm{C} ;{ }^{1} \mathrm{H}$ NMR $\left(300 \mathrm{MHz}, \mathrm{CDCl}_{3}\right) \delta 1.33$ $(3 \mathrm{H}, \mathrm{t}, J=7.2 \mathrm{~Hz}), 3.83(3 \mathrm{H}, \mathrm{s}, \mathrm{OMe}), 3.86(3 \mathrm{H}, \mathrm{s}, \mathrm{OMe}), 4.24\left(2 \mathrm{H}, \mathrm{q}, J=6.9 \mathrm{~Hz}, \mathrm{OCH}_{2}\right), 6.42$ $(1 \mathrm{H}, \mathrm{d}, J=15.6 \mathrm{~Hz}$, trans ethenyl C1-H), $6.44(1 \mathrm{H}, \mathrm{s}, \mathrm{C} 3-\mathrm{H}), 6.49(1 \mathrm{H}, \mathrm{d}, J=8.4 \mathrm{~Hz}, \mathrm{C} 5-\mathrm{H}), 7.43$ $(1 \mathrm{H}, \mathrm{d}, J=8.7 \mathrm{~Hz}, \mathrm{C} 6-\mathrm{H}), 7.89\left(1 \mathrm{H}, \mathrm{d}, J=16.0 \mathrm{~Hz}\right.$, trans ethenyl C2-H); ${ }^{13} \mathrm{C}$ NMR $(75 \mathrm{MHz}$, $\left.\mathrm{CDCl}_{3}\right) \delta 14.8\left(\mathrm{CH}_{3}\right), 55.7(\mathrm{OMe}), 55.8(\mathrm{OMe}), 60.5\left(\mathrm{OCH}_{2}\right), 98.6(\mathrm{C} 3), 105.3(\mathrm{C} 5), 116.3$ (trans ethenyl C1), 116.8 (C1), 130.6 (C6), 140.1 (trans ethenyl C2), 159.9 (C2), 162.7 (C4), 168.1 $(\mathrm{C}=\mathrm{O})$; Anal. Calcd for $\mathrm{C}_{13} \mathrm{H}_{16} \mathrm{O}_{4}$ (236.26): C, 66.09; H, 6.83\% Found: C, 65.98, H, 6.65\% Z-5: $\mathrm{R}_{f} 0.59$ (EtOAc:hexane=1:3); colorless oil; ${ }^{1} \mathrm{H}$ NMR $\left(300 \mathrm{MHz}, \mathrm{CDCl}_{3}\right) \delta 1.24(3 \mathrm{H}, \mathrm{t}, \mathrm{J}=7.2 \mathrm{~Hz})$, $3.81(3 \mathrm{H}, \mathrm{s}, \mathrm{OMe}), 3.82(3 \mathrm{H}, \mathrm{s}, \mathrm{OMe}), 4.15\left(2 \mathrm{H}, \mathrm{q}, J=7.2 \mathrm{~Hz}, \mathrm{OCH}_{2}\right), 5.85(1 \mathrm{H}, \mathrm{d}, J=12.6 \mathrm{~Hz}$, cis ethenyl C1-H), $6.41(1 \mathrm{H}, \mathrm{s}, \mathrm{C} 3-\mathrm{H}), 6.46(1 \mathrm{H}, \mathrm{d}, J=8.4 \mathrm{~Hz}, \mathrm{C} 5-\mathrm{H}), 7.12(1 \mathrm{H}, \mathrm{d}, J=12.3 \mathrm{~Hz}$, cis ethenyl C2-H), $7.70(1 \mathrm{H}, \mathrm{d}, J=8.7 \mathrm{~Hz}, \mathrm{C} 6-\mathrm{H}) ;{ }^{13} \mathrm{C}$ NMR $\left(75 \mathrm{MHz}, \mathrm{CDCl}_{3}\right) \delta 14.6\left(\mathrm{CH}_{3}\right), 55.7$ $(\mathrm{OMe}), 55.8(\mathrm{OMe}), 60.3\left(\mathrm{OCH}_{2}\right), 98.0(\mathrm{C} 3), 104.1(\mathrm{C} 5), 116.9$ (trans ethenyl $\left.\mathrm{C} 1\right), 117.8(\mathrm{C} 1)$, 132.2 (C6), 138.9 (trans ethenyl C2), $158.8(\mathrm{C} 2), 162.0(\mathrm{C} 4), 166.7(\mathrm{C}=\mathrm{O})$; Anal. Calcd for $\mathrm{C}_{13} \mathrm{H}_{16} \mathrm{O}_{4}$ (236.26): C, 66.09; H, 6.83\% Found: $\mathrm{C}, 66.05, \mathrm{H}, 6.61 \%$

1-(2-Carbethoxyethyl)-2,4-dimethoxybenzene (6). To a solution $3 \mathbf{b}(1.30 \mathrm{~g}, 5.50 \mathrm{mmol})$ in THF $(30 \mathrm{~mL})$ was added $\mathrm{Pd} / \mathrm{C}(0.41 \mathrm{~g}, 10 \mathrm{wt} \%$ dry basis on activated carbon $)$ and the mixture stirred for $10 \mathrm{~h}$ at $\mathrm{rt}$ under hydrogen atmosphere with a hydrogen balloon. The reaction mixture was filtered through Celite, the solvent was removed by evaporation and the residue was extracted with $\mathrm{CH}_{2} \mathrm{Cl}_{2}$, washed with brine, dried and concentrated to give an oil. The crude residue was purified by chromatography (EtOAc:hexane $=1: 4)$ to give a colorless oil 6 (1.30 g, 99\%). $\mathrm{R}_{f} 0.65$ (EtOAc:hexane=1:3); ${ }^{1} \mathrm{H}$ NMR $\left(300 \mathrm{MHz}, \mathrm{CDCl}_{3}\right) \delta 1.24(3 \mathrm{H}, \mathrm{t}, J=7.2 \mathrm{~Hz}), 2.55$ $(2 \mathrm{H}, \mathrm{t}, J=7.5 \mathrm{~Hz}$, ethyl C1-H), $2.86(2 \mathrm{H}, \mathrm{t}, J=7.5 \mathrm{~Hz}$, ethyl C2-H), $3.78(3 \mathrm{H}, \mathrm{s}, \mathrm{OMe}), 3.79(3 \mathrm{H}, \mathrm{s}$, OMe), $4.11\left(2 \mathrm{H}, \mathrm{q}, J=6.9 \mathrm{~Hz}, \mathrm{OCH}_{2}\right), 6.39(1 \mathrm{H}, \mathrm{d}, J=8.4 \mathrm{~Hz}, \mathrm{C} 5-\mathrm{H}), 6.42(1 \mathrm{H}, \mathrm{s}, \mathrm{C} 3-\mathrm{H}), 7.03$ $(1 \mathrm{H}, \mathrm{d}, J=8.4 \mathrm{~Hz}, \mathrm{C} 6-\mathrm{H}) ;{ }^{13} \mathrm{C} \mathrm{NMR}\left(75 \mathrm{MHz}, \mathrm{CDCl}_{3}\right) \delta 14.6\left(\mathrm{CH}_{3}\right), 25.9$ (ethyl C1), 34.9 (ethyl C-2), 55.5 (OMe), 55.7 (OMe), $60.5\left(\mathrm{OCH}_{2}\right), 98.7$ (C3), 103.9 (C5), 121.5 (C1), 130.3 (C6), 158.5 (C4), 159.6 (C2), $173.6(\mathrm{C}=\mathrm{O})$; Anal. Calcd for $\mathrm{C}_{13} \mathrm{H}_{18} \mathrm{O}_{4}$ (238.28): C, 65.53; H, 7.61\% Found: C, 65.37, H, 7.49\% 
1-(3-Hydroxypropyl)-2,4 dimethoxybenzene (7). To a solution of $\mathrm{LiAlH}_{4}(0.33 \mathrm{~g}, 8.22 \mathrm{mmol})$ in THF $(20 \mathrm{~mL})$ was slowly added $6(1.30 \mathrm{~g}, 5.48 \mathrm{mmol})$ and the mixture stirred for $30 \mathrm{~min}$ at $0{ }^{\circ} \mathrm{C}$. The reaction was quenched by addition of $1 \mathrm{~N} \mathrm{NaOH}$ solution and filtered using Celite. The solvent was removed by evaporation and the organic phase was extracted with EtOAc, washed with brine, dried and concentrated to give a crude liquid, which was purified by chromatography (EtOAc:hexane=1:2) to give a colorless liquid 7 (1.05 g, 98\%). $\mathrm{R}_{f} 0.22$ (EtOAc:hexane=1:3); ${ }^{1} \mathrm{H}$ NMR (300 MHz, CDCl $) \delta 1.80(2 \mathrm{H}, \mathrm{m}$, propyl C2-H), $2.65(2 \mathrm{H}, \mathrm{t}, J=7.2 \mathrm{~Hz}$, propyl C1-H), $3.58(2 \mathrm{H}, \mathrm{t}, J=6.3 \mathrm{~Hz}$, propyl C3-H), $3.79(3 \mathrm{H}, \mathrm{s}), 3.80(3 \mathrm{H}, \mathrm{s}), 6.43(1 \mathrm{H}, \mathrm{d}, J=7.5 \mathrm{~Hz}, \mathrm{C} 5-\mathrm{H})$, $6.44(1 \mathrm{H}, \mathrm{s}, \mathrm{C} 3-\mathrm{H}), 7.03(1 \mathrm{H}, \mathrm{d}, J=7.5 \mathrm{~Hz}, \mathrm{C} 6-\mathrm{H}) ;{ }^{13} \mathrm{C} \mathrm{NMR}\left(75 \mathrm{MHz}, \mathrm{CDCl}_{3}\right) \delta 25.6$ (propyl C2), 33.5 (propyl C1), $55.7\left(2 \mathrm{xOCH}_{3}\right), 62.2\left(\mathrm{OCH}_{2}\right), 98.7$ (C3), $104.3(\mathrm{C} 5), 122.4$ (C1), 130.5 (C6), 158.3 (C4), 159.3 (C2); Anal. Calcd for $\mathrm{C}_{11} \mathrm{H}_{16} \mathrm{O}_{3}$ (196.24): C, 67.32; H, 8.22\% Found: C, $67.17, \mathrm{H}, 8.07 \%$

1-(3-Benzyloxypropyl)-2,4-dimethoxybenzene (8). To a solution of 7 (0.88 g, $4.49 \mathrm{mmol})$ in THF $(20 \mathrm{~mL})$ was added $\mathrm{NaH}(0.54 \mathrm{~g}, 13.5 \mathrm{mmol})$ with $\mathrm{BnBr}(0.80 \mathrm{~mL}, 6.73 \mathrm{mmol})$ and the mixture heated at reflux for $10 \mathrm{~h}$. Then, the solution was filtered through Celite, the solvent was removed by evaporation and the organic product was extracted with $\mathrm{CH}_{2} \mathrm{Cl}_{2}$, washed with brine, dried and concentrated to give a crude liquid, which was purified by chromatography (EtOAc:hexane=1:7) to give the colorless liquid 8 (1.10 g, 86\%). $\mathrm{R}_{f} 0.67$ (EtOAc:hexane=1:3); ${ }^{1} \mathrm{H}$ NMR $\left(300 \mathrm{MHz}, \mathrm{CDCl}_{3}\right) \delta 1.87(2 \mathrm{H}, \mathrm{m}), 2.63(2 \mathrm{H}, \mathrm{t}, J=7.5 \mathrm{~Hz}), 3.48(2 \mathrm{H}, \mathrm{t}, J=6.6 \mathrm{~Hz}), 3.77$ $(3 \mathrm{H}, \mathrm{s}), 3.78(3 \mathrm{H}, \mathrm{s}), 4.50(2 \mathrm{H}, \mathrm{s}$, benzyl-CH$), 6.39(1 \mathrm{H}, \mathrm{d}, J=8.1 \mathrm{~Hz}, \mathrm{C} 5-\mathrm{H}), 6.42(1 \mathrm{H}, \mathrm{s}, \mathrm{C} 3-\mathrm{H})$, $6.99(1 \mathrm{H}, \mathrm{d}, J=7.8 \mathrm{~Hz}, \mathrm{C} 6-\mathrm{H}), 7.24-7.34(5 \mathrm{H}, \mathrm{m}) ;{ }^{13} \mathrm{C} \mathrm{NMR}\left(75 \mathrm{MHz}, \mathrm{CDCl}_{3}\right) \delta 26.6$ (propyl C2), 30.2 (propyl C1), $55.5\left(\mathrm{OCH}_{3}\right), 55.7\left(\mathrm{OCH}_{3}\right), 70.3\left(\mathrm{OCH}_{2}\right), 73.1\left(\mathrm{OCH}_{2} \mathrm{Ph}\right), 98.7(\mathrm{C} 3), 103.8$ (C5), 122.9 (C1), 127.6 (benzyl C4), 127.9 (x2), 128.5 (x2), 130.3 (C6), 138.9 (benzyl C1), 158.5 (C4), 159.2 (C2); Anal. Calcd for $\mathrm{C}_{18} \mathrm{H}_{22} \mathrm{O}_{3}$ (286.37): C, 75.50; H, 7.74. Found: C, 75.38, $\mathrm{H}, 7.65$.

1-(3-Benzyloxypropyl)-5-iodo-2,4-dimethoxybenzene (9b). To a solution of 8 (0.77 g, $2.69 \mathrm{mmol})$ in EtOH $(40 \mathrm{~mL})$ was added $\mathrm{I}_{2}(0.82 \mathrm{~g}, 3.22 \mathrm{mmol})$ and silver sulfate $(1.01 \mathrm{~g}$, $3.22 \mathrm{mmol}$ ) and stirred for $2 \mathrm{~h}$ at $\mathrm{rt}$. Solvent was removed by evaporation and the organic residue was extracted with $\mathrm{CH}_{2} \mathrm{Cl}_{2}$, washed with brine, dried and concentrated to give the solid. The solid was purified by chromatography (EtOAc:hexane=1:4) to give the white solid 9 (0.98 g, 88\%). $\mathrm{R}_{f} 0.58$ (EtOAc:hexane=1:3); mp 57-59 ${ }^{\circ} \mathrm{C} ;{ }^{1} \mathrm{H}$ NMR $\left(300 \mathrm{MHz}, \mathrm{CDCl}_{3}\right) \delta 1.85$ (2H, m), $2.59(2 \mathrm{H}, \mathrm{t}, J=7.5 \mathrm{~Hz}), 3.46(2 \mathrm{H}, \mathrm{t}, J=6.6 \mathrm{~Hz}), 3.80(3 \mathrm{H}, \mathrm{s}), 3.86(3 \mathrm{H}, \mathrm{s}), 4.49(2 \mathrm{H}, \mathrm{s}), 6.38(1 \mathrm{H}, \mathrm{s}$, $\mathrm{C} 3-\mathrm{H}), 7.24-7.35(5 \mathrm{H}, \mathrm{m}), 7.45(1 \mathrm{H}, \mathrm{s}, \mathrm{C} 6-\mathrm{H}) ;{ }^{13} \mathrm{C} \mathrm{NMR}\left(75 \mathrm{MHz}, \mathrm{CDCl}_{3}\right) \delta 26.3,30.1,55.8$, 56.8, 70.1, 73.2, 74.0 (C5-I), 96.0 (C3), 125.1 (C1), 127.7, 127.9 (x2), 128.6 (x2), 138.8, 139.5 (C6), 157.5 (C2), 159.0 (C4); Anal. Calcd for $\mathrm{C}_{18} \mathrm{H}_{21} \mathrm{IO}_{3}$ (412.26): C, 52.44; H, 5.13; I, 30.78\% Found: C, 52.28, H, 5.06; I, 30.53\%

4-Benzyloxy-3-methoxyphenylacetylene (10). To a stirred mixture of trimethylsilyldiazomethane $(2 \mathrm{M}$ solution in dichloromethane, $6 \mathrm{~mL})$ at $-78{ }^{\circ} \mathrm{C}$ in $\mathrm{THF}(45 \mathrm{~mL})$ was added $n$-BuLi $(5.1 \mathrm{~mL}, 1.6 \mathrm{M}$ in hexane) and the mixture left for $0.5 \mathrm{~h}$. 4-Benzyloxy-3methoxybenzaldehyde $(3.00 \mathrm{~g}, 12.4 \mathrm{mmol})$ in THF $(150 \mathrm{~mL})$ was added and the mixture stirred 
for $3 \mathrm{~h}$ at the same temperature. The mixture was then quenched with saturated $\mathrm{NH}_{4} \mathrm{Cl}$, the organic phase was extracted with diethyl ether, washed with brine, dried and concentrated to give a solid. The solid was purified by chromatography (EtOAc:hexane=1:7) to give $\mathbf{1 0}$ as a yellow solid (2.90 g, 99\%). $\mathrm{R}_{f} 0.63$ (EtOAc:hexane=1:3); mp 82-84 ${ }^{\circ} \mathrm{C} ;{ }^{1} \mathrm{H}$ NMR $\left(300 \mathrm{MHz}, \mathrm{CDCl}_{3}\right) \delta$ $2.99\left(1 \mathrm{H}, \mathrm{s}\right.$, acetylene), $3.87(3 \mathrm{H}, \mathrm{s}, \mathrm{OMe}), 5.15\left(2 \mathrm{H}, \mathrm{s}, \mathrm{OCH}_{2}\right), 6.79(1 \mathrm{H}, \mathrm{d}, J=8.1 \mathrm{~Hz}), 7.01(2 \mathrm{H}$, $\mathrm{d}, J=8.1 \mathrm{~Hz}), 7.33-7.39\left(5 \mathrm{H}, \mathrm{m}\right.$, benzyl); ${ }^{13} \mathrm{C} \mathrm{NMR}\left(75 \mathrm{MHz}, \mathrm{CDCl}_{3}\right) \delta 56.3(\mathrm{OMe}), 71.1$ $\left(\mathrm{OCH}_{2} \mathrm{Ph}\right), 76.1$ (acetylene), 84.0 (acetylene), 113.7 (C5), 114.9 (C1), 115.4 (C2), 125.5 (C6), 127.4, 128.2 (x2), 128.8 (x2), 136.8, 149.1 (C3), 149.3 (C4); Anal. Calcd for $\mathrm{C}_{16} \mathrm{H}_{14} \mathrm{O}_{2}(238.28)$ : C, 80.65; H, 5.92\% Found: C, 80.29, H, 5.66\%

\section{1-(4-Benzyloxy-3-methoxyphenyl)-2-[5-(3-benzyloxypropyl)-2,4-dimethoxyphenyl]acetylene} (11). To a solution of $9 b(0.23 \mathrm{~g}, 0.56 \mathrm{mmol}), \mathrm{PdCl}_{2}\left(\mathrm{PPh}_{3}\right)_{2}(0.019 \mathrm{~g}, 0.03 \mathrm{mmol})$, 4-benzyloxy3-methoxyphenylacetylene (10, $0.20 \mathrm{~g}, 0.84 \mathrm{mmol})$ and $\mathrm{CuI}(0.005 \mathrm{~g}, 0.03 \mathrm{mmol})$ in $\mathrm{DMF}$ $(3 \mathrm{~mL})$ was added $\mathrm{Et}_{3} \mathrm{~N}(0.16 \mathrm{~mL}, 1.12 \mathrm{mmol})$ and the mixture stirred for $48 \mathrm{~h}$ at $\mathrm{rt}$. The reaction mixture was extracted with $\mathrm{CHCl}_{3}$, washed with brine, dried and concentrated to give the crude oil. The crude product was purified by chromatography (EtOAc:hexane=1:4) to give a brownish oil 11 (0.27 g, 92\%). $\mathrm{R}_{f} 0.40$ (EtOAc:hexane=1:3); ${ }^{1} \mathrm{H} \mathrm{NMR}\left(300 \mathrm{MHz}, \mathrm{CDCl}_{3}\right) \delta 1.88(2 \mathrm{H}, \mathrm{m})$, $2.62(2 \mathrm{H}, \mathrm{t}, \mathrm{J}=7.5 \mathrm{~Hz}), 3.48(2 \mathrm{H}, \mathrm{t}, \mathrm{J}=6.3 \mathrm{~Hz}), 3.84(3 \mathrm{H}, \mathrm{s}), 3.89(3 \mathrm{H}, \mathrm{s}), 3.91(3 \mathrm{H}, \mathrm{s}), 4.50(2 \mathrm{H}$, s), $5.16(2 \mathrm{H}, \mathrm{s}), 6.40(1 \mathrm{H}, \mathrm{s}, \mathrm{C} 3 \mathrm{\prime}-\mathrm{H}), 6.81(1 \mathrm{H}, \mathrm{d}, \mathrm{J}=8.7 \mathrm{~Hz}, \mathrm{C} 4-\mathrm{H}), 7.05(1 \mathrm{H}, \mathrm{d}, \mathrm{J}=6.6 \mathrm{~Hz}, \mathrm{C} 5-\mathrm{H})$, $7.06(1 \mathrm{H}, \mathrm{s}, \mathrm{C} 1-\mathrm{H}), 7.23-7.43(10 \mathrm{H}, \mathrm{m}), 7.41\left(1 \mathrm{H}, \mathrm{C} 6{ }^{\prime}-\mathrm{H}\right) ;{ }^{13} \mathrm{C} \mathrm{NMR}\left(75 \mathrm{MHz}, \mathrm{CDCl}_{3}\right) \delta 26.4$, 30.0, 55.7, 56.3, 56.4, 70.2, 71.1, 73.1, 84.8 (acetylene), 92.1 (acetylene), 95.1 (C3'), 103.9, $113.7,114.9,116.9,122.7,124.8,127.5$ (x2), 127.7, 127.9 (x2), 128.1, 128.5 (x2), 128.8 (x2), 134.5, 137.0, 138.8, 148.3, 149.2, 158.8, 159.7; Anal. Calcd for $\mathrm{C}_{34} \mathrm{H}_{34} \mathrm{O}_{5}$ (522.63): C, 78.14; $\mathrm{H}$, 6.56\% Found: C, 77.96, H, 6.35\%

\section{2-(4-Benzyloxy-3-methoxyphenyl)-5-(3-benzyloxypropyl)-3-iodo-6-methoxybenzofuran (12).}

To a solution of $11(1.20 \mathrm{~g}, 2.30 \mathrm{mmol})$ in $\mathrm{CHCl}_{3}(50 \mathrm{~mL})$ was slowly added $\mathrm{I}_{2}(1.17 \mathrm{~g}$, $4.59 \mathrm{mmol}$ ) at $-20{ }^{\circ} \mathrm{C}$ and stirred for $5 \mathrm{~h}$ at $\mathrm{rt}$. After addition of aqueous $\mathrm{NaHCO}_{3}$, the reaction mixture was extracted with $\mathrm{CHCl}_{3}$, washed with brine, dried and concentrated to give a solid. The crude solid was purified by chromatography (EtOAc:hexane=1:3) to give $\mathbf{1 2}$ as a white solid (1.20 g, 82\%). $\mathrm{R}_{f} 0.64$ (EtOAc:hexane=1:3); mp 134-136 ${ }^{\circ} \mathrm{C} ;{ }^{1} \mathrm{H}$ NMR $\left(300 \mathrm{MHz}, \mathrm{CDCl}_{3}\right) \delta 1.96$ $(2 \mathrm{H}, \mathrm{m}), 2.81(2 \mathrm{H}, \mathrm{t}, J=7.5 \mathrm{~Hz}), 3.52(2 \mathrm{H}, \mathrm{t}, J=6.3 \mathrm{~Hz}), 3.85(3 \mathrm{H}, \mathrm{s}), 3.98(3 \mathrm{H}, \mathrm{s}), 4.52(2 \mathrm{H}, \mathrm{s})$, $5.20(2 \mathrm{H}, \mathrm{s}), 6.94(1 \mathrm{H}, \mathrm{d}, J=8.7 \mathrm{~Hz}, \mathrm{C} 4 '-\mathrm{H}), 6.96(1 \mathrm{H}, \mathrm{s}, \mathrm{C} 7-\mathrm{H}), 7.12(1 \mathrm{H}, \mathrm{s}), 7.23-7.44(10 \mathrm{H}, \mathrm{m})$, $7.64(1 \mathrm{H}, \mathrm{dd}, J=1.8,8.4 \mathrm{~Hz}, \mathrm{C} 5 '-\mathrm{H}), 7.68(1 \mathrm{H}$, br s)$){ }^{13} \mathrm{C} \mathrm{NMR}\left(75 \mathrm{MHz}, \mathrm{CDCl}_{3}\right) \delta 27.7,30.3$, $56.1,56.4,59.8,70.3,71.2,73.2,93.8,110.7,113.6,120.1,121.8,123.8,125.2,127.5$ (x2), 127.7, 127.9 (x2), 128.1, 128.2, 128.6 (x2), 128.8 (x2), 137.0, 138.9, 148.7, 149.4, 151.8, 153.2, 157.1; Anal. Calcd for $\mathrm{C}_{33} \mathrm{H}_{31} \mathrm{IO}_{5}$ (634.50): C, 62.47; H, 4.92; I, 20.00\% Found: $\mathrm{C}, 61.97$, H, 4.65 ; I, 20.11\%

\section{2-(4-Benzyloxy-3-methoxyphenyl)-5-(3-benzyloxypropyl)-6-methoxybenzofuran-3-}

carbaldehyde (13). To a solution of $12(0.06 \mathrm{~g}, 0.09 \mathrm{mmol})$ in toluene $(5 \mathrm{~mL})$ was added $N$ formylpiperidine $(0.10 \mathrm{~mL}, 0.95 \mathrm{mmol})$ and $t$-BuLi $(0.56 \mathrm{~mL}, 1.7 \mathrm{M}$ in pentane $)$ and the mixture was stirred for $1 \mathrm{~h}$ at $0{ }^{\circ} \mathrm{C}$. After the solution was neutralized with $1 \mathrm{~N} \mathrm{HCl}$, the mixture was 
extracted with diethyl ether, the extract washed with brine, dried and concentrated to give a solid. The solid was purified by chromatography (EtOAc:hexane=1:4) to give $\mathbf{1 3}$ as a yellow solid (0.037 g, 74\%). $\mathrm{R}_{f} 0.43$ (EtOAc:hexane=1:3); mp 98-100 ${ }^{\circ} \mathrm{C} ;{ }^{1} \mathrm{H}$ NMR (300 MHz, $\left.\mathrm{CDCl}_{3}\right) \delta 1.96$ $(2 \mathrm{H}, \mathrm{m}), 2.81(2 \mathrm{H}, \mathrm{t}, J=7.5 \mathrm{~Hz}), 3.53(2 \mathrm{H}, \mathrm{t}, J=6.3 \mathrm{~Hz}), 3.87(3 \mathrm{H}, \mathrm{s}), 3.99(3 \mathrm{H}, \mathrm{s}), 4.52(2 \mathrm{H}, \mathrm{s})$, $5.25(2 \mathrm{H}, \mathrm{s}), 7.00(1 \mathrm{H}, \mathrm{d}, J=6.9 \mathrm{~Hz}, \mathrm{C} 5 ' \mathrm{H}), 7.01(1 \mathrm{H}, \mathrm{s}, \mathrm{C} 7-\mathrm{H}), 7.24-7.47(12 \mathrm{H}, \mathrm{m}), 8.00(1 \mathrm{H}, \mathrm{s}$, C4-H), $10.26(1 \mathrm{H}, \mathrm{s}, \mathrm{CHO}) ;{ }^{13} \mathrm{C} \mathrm{NMR}\left(75 \mathrm{MHz}, \mathrm{CDCl}_{3}\right) \delta 27.8,30.3,55.9,56.5,70.4,71.2,73.1$, 93.7, 111.7, 113.7, 117.1, 118.1, 122.1, 122.4, 122.6, 127.4 (x2), 127.6, 127.9 (x2), 128.3, 128.5, 128.8 (x2), 128.9 (x2), 136.5, 138.9, 150.0, 150.6, 153.7, 157.1, 164.4, 186.9 (CHO); Anal. Calcd for $\mathrm{C}_{34} \mathrm{H}_{32} \mathrm{O}_{6}$ (536.61): C, 76.10; H, 6.01\% Found: C, 75.99, H, 5.89\%

\section{2-(4-Hydroxy-3-methoxyphenyl)-5-(3-hydroxypropyl)-6-methoxybenzofuran-3-}

carbaldehyde (2). To a solution of $13(0.82 \mathrm{~g}, 0.15 \mathrm{mmol})$ in $\mathrm{CH}_{2} \mathrm{Cl}_{2}(20 \mathrm{~mL})-78{ }^{\circ} \mathrm{C}$ was added $\mathrm{BBr}_{3}\left(0.30 \mathrm{~mL}, 1.0 \mathrm{M}\right.$ in $\left.\mathrm{CH}_{2} \mathrm{Cl}_{2}\right)$ and the mixture stirred for $1 \mathrm{~h}$. The organic phase was extracted with $\mathrm{CH}_{2} \mathrm{Cl}_{2}$, the extract washed with brine, dried and concentrated to give a crude solid. The solid was purified by chromatography $\left(\mathrm{MeOH}: \mathrm{CHCl}_{3}=1: 15\right)$ to give the pure product as a yellow solid 2 (0.04 g, 74\%). $\mathrm{R}_{f} 0.48\left(\mathrm{MeOH}: \mathrm{CHCl}_{3}=1: 15\right)$; mp 200-202 ${ }^{\circ} \mathrm{C} ;{ }^{1} \mathrm{H}$ NMR $(300$ $\left.\mathrm{MHz}, \mathrm{CD}_{3} \mathrm{OD}\right) \delta 1.84(2 \mathrm{H}, \mathrm{m}$, propyl C2-H), $2.76(2 \mathrm{H}, \mathrm{t}, J=7.8 \mathrm{~Hz}$, propyl C1-H), 3.59 (2H, t, $\left.J=6.6 \mathrm{~Hz}, \mathrm{CH}_{2} \mathrm{OH}\right), 3.90\left(3 \mathrm{H}, \mathrm{s}, \mathrm{C}^{\prime}-\mathrm{OCH}_{3}\right), 3.95\left(3 \mathrm{H}, \mathrm{s}, \mathrm{C} 6-\mathrm{OCH}_{3}\right), 6.97(1 \mathrm{H}, \mathrm{d}, \mathrm{J}=8.4 \mathrm{~Hz}, \mathrm{C} 5 '-$ H), 7.18 (1H, s, C7-H), 7.36 (1H, dd, J=2.1, 8.4 Hz, C6'-H), 7.43 (1H, d, J=2.1 Hz, C2'-H), 7.88 $(1 \mathrm{H}, \mathrm{s}, \mathrm{C} 4-\mathrm{H}), 10.20(1 \mathrm{H}, \mathrm{s}, \mathrm{CHO}) ;{ }^{13} \mathrm{C} \mathrm{NMR}\left(75 \mathrm{MHz}, \mathrm{DMSO}-d_{6}\right) \delta 27.4$ (propyl C2), 33.7 (propyl C1), $56.5\left(\mathrm{C}^{\prime}-\mathrm{OCH}_{3}\right), 56.6\left(\mathrm{C}^{-}-\mathrm{OCH}_{3}\right), 61.1\left(\mathrm{CH}_{2} \mathrm{OH}\right), 95.1(\mathrm{C} 7), 112.6\left(\mathrm{C}^{\prime}\right), 116.1$ (C5'), 116.7 (C5), 118.1 (C4), 119.8 (C6'), 121.9 (C3a), 123.2 (C1'), 128.6 (C3), 148.7 (C4'), 150.3 (C3'), 153.4 (C6), 156.9 (C7a), 164.8 (C2), 187.4 (CHO). Anal. Calcd for $\mathrm{C}_{20} \mathrm{H}_{20} \mathrm{O}_{6}$ (356.37): C, 67.41; H, 5.66\%. Found: C, 67.05; H, 5.52\%

1-(2-Carbethoxyethenyl)-2,5-dimethoxybenzene (15). To a solution of 2,5dimethoxybenzaldehyde (14) $(1.00 \mathrm{~g}, 6.02 \mathrm{mmol})$ in $\mathrm{CH}_{2} \mathrm{Cl}_{2}(100 \mathrm{~mL})$ under a nitrogen atmosphere was added (carbethoxymethylene)triphenylphosphorane $(3.31 \mathrm{~g}, 9.03 \mathrm{mmol}$ ) and the mixture heated at reflux for 3 days. Solvent was removed by evaporation and the organic product was extracted into $\mathrm{CH}_{2} \mathrm{Cl}_{2}$, the extract washed with brine, dried and concentrated to give an oil which was purified by chromatography (EtOAc:hexane=1:4) to give the yellow oil 15 (1.40 g, 99\%, E:Z=24:1). E-15: $\mathrm{R}_{f} 0.58$ (EtOAc:hexane=1:2); ${ }^{1} \mathrm{H} \mathrm{NMR}\left(300 \mathrm{MHz}, \mathrm{CDCl}_{3}\right) \delta 1.34(3 \mathrm{H}, \mathrm{t}$, $J=7.2 \mathrm{~Hz}), 3.78(3 \mathrm{H}, \mathrm{s}, \mathrm{OMe}), 3.84(3 \mathrm{H}, \mathrm{s}, \mathrm{OMe}), 4.26\left(2 \mathrm{H}, \mathrm{q}, J=7.2 \mathrm{~Hz}, \mathrm{OCH}_{2}\right), 6.48(1 \mathrm{H}, \mathrm{d}$, $J=15.9 \mathrm{~Hz}$, trans ethenyl C1-H), 6.82-6.92 (2H, m), $7.03(1 \mathrm{H}, \mathrm{d}, J=3.0 \mathrm{~Hz}), 7.95(1 \mathrm{H}, \mathrm{d}, J=16.2$ $\mathrm{Hz}$, trans ethenyl $\mathrm{C} 2-\mathrm{H}) ;{ }^{13} \mathrm{C} \mathrm{NMR}\left(75 \mathrm{MHz}, \mathrm{CDCl}_{3}\right) \delta 14.8\left(\mathrm{CH}_{3}\right), 56.1(\mathrm{OMe}), 56.4(\mathrm{OMe})$, $60.7\left(\mathrm{OCH}_{2}\right), 112.6(\mathrm{C} 4), 113.4(\mathrm{C} 3), 117.2$ (C6), 119.2 (trans ethenyl C2), $124.1(\mathrm{C} 1), 139.9$ (trans ethenyl C1), 152.9 (C2), 153.6 (C5), $167.5(\mathrm{C}=\mathrm{O})$; Anal. Calcd for $\mathrm{C}_{13} \mathrm{H}_{16} \mathrm{O}_{4}$ (236.26): C, 66.09; H, 6.83\% Found: C, 65.97, H, 6.51\% Z-15: $\mathrm{R}_{f} 0.64$ (EtOAc:hexane=1:2); ${ }^{1} \mathrm{H}$ NMR (300 $\left.\mathrm{MHz} \mathrm{CDCl}_{3}\right) \delta 1.21(3 \mathrm{H}, \mathrm{t}, J=7.2 \mathrm{~Hz}), 3.81(3 \mathrm{H}, \mathrm{s}, \mathrm{OMe}), 3.78(3 \mathrm{H}, \mathrm{s}, \mathrm{OMe}), 4.14(2 \mathrm{H}, \mathrm{q}, J=7.2$ $\left.\mathrm{Hz}, \mathrm{OCH}_{2}\right), 5.96(1 \mathrm{H}, \mathrm{d}, J=12.6 \mathrm{~Hz}$, cis ethenyl C1-H), 6.77-6.82 $(2 \mathrm{H}, \mathrm{m}), 7.11(1 \mathrm{H}, \mathrm{d}, J=12.6$ $\mathrm{Hz}$, cis ethenyl C2-H), $7.20(1 \mathrm{H}, \mathrm{d}, J=3.0 \mathrm{~Hz}) ;{ }^{13} \mathrm{C} \mathrm{NMR}\left(75 \mathrm{MHz}, \mathrm{CDCl}_{3}\right) \delta 14.5,56.1,56.4$, 
60.5, 111.6, 115.8, 116.2, 120.5, 124.9, 138.6, 151.7, 152.9, 166.4; Anal. Calcd for $\mathrm{C}_{13} \mathrm{H}_{16} \mathrm{O}_{4}$ (236.26): C, 66.09; H, 6.83\% Found: C, 65.89, H, 6.57\%

1-(2-Carbethoxyethyl)-2,5-dimethoxybenzene (16). To a solution $15(1.61 \mathrm{~g}, 6.80 \mathrm{mmol})$ in THF $(50 \mathrm{~mL})$ was added $\mathrm{Pd} / \mathrm{C}(0.51 \mathrm{~g}, 10 \mathrm{wt} \%$ dry basis on activated carbon) with a hydrogen balloon and the mixture stirred $10 \mathrm{~h}$ at $\mathrm{rt}$. After the solution was filtered using Celite, the solvent was removed by evaporation and the organic product was extracted with $\mathrm{CH}_{2} \mathrm{Cl}_{2}$, the extract washed with brine, dried and concentrated to give a liquid. The liquid was purified by chromatography (EtOAc:hexane $=1: 4)$ to give $\mathbf{1 6}$ as a colorless oil $(1.55 \mathrm{~g}, 96 \%) . \mathrm{R}_{f} 0.72$ (EtOAc:hexane=1:2); ${ }^{1} \mathrm{H}$ NMR $\left(300 \mathrm{MHz}, \mathrm{CDCl}_{3}\right) \delta 1.25(3 \mathrm{H}, \mathrm{t}, J=7.2 \mathrm{~Hz}), 2.59(2 \mathrm{H}, \mathrm{t}, J=8.1$ $\mathrm{Hz}$, ethyl C1-H), 2.90 ( $2 \mathrm{H}, \mathrm{t}, J=8.1 \mathrm{~Hz}$, ethyl C2-H), 3.75 (3H, s, OMe), 3.77 (3H, s, OMe), 4.12 $\left(2 \mathrm{H}, \mathrm{q}, J=7.2 \mathrm{~Hz}, \mathrm{OCH}_{2}\right), 6.67-6.77(3 \mathrm{H}, \mathrm{m}) ;{ }^{13} \mathrm{C} \mathrm{NMR}\left(75 \mathrm{MHz}, \mathrm{CDCl}_{3}\right) \delta 14.7\left(\mathrm{CH}_{3}\right), 26.6$ (ethyl C1), 34.6 (ethyl C-2), $56.0(\mathrm{OMe}), 56.1(\mathrm{OMe}), 60.6\left(\mathrm{OCH}_{2}\right), 111.2(\mathrm{C} 4), 111.6(\mathrm{C} 3)$, 116.5 (C6), 130.2 (C1), 151.9 (C2), 153.5 (C5), $173.5(\mathrm{C}=\mathrm{O})$; Anal. Calcd for $\mathrm{C}_{13} \mathrm{H}_{18} \mathrm{O}_{4}$ (238.28): C, 65.53; H, 7.61\% Found: C, 65.33, H, 7.35\%

1-(3-Hydroxypropyl)-2,5 dimethoxybenzene (17). To a solution of $\mathrm{LiAlH}_{4}(0.51 \mathrm{~g}, 12.8 \mathrm{mmol})$ in THF $(20 \mathrm{~mL})$ under nitrogen was slowly added $16(2.04 \mathrm{~g}, 8.56 \mathrm{mmol})$ and the resulting mixture stirred for $30 \mathrm{~min}$ at $0{ }^{\circ} \mathrm{C}$. The reaction was quenched by addition of $1 \mathrm{~N} \mathrm{NaOH}$ solution and filtered using Celite filter. The solvent was removed by evaporation and the organic product was extracted using EtOAc, the extract washed with brine, dried and concentrated to give a liquid, which was purified by chromatography (EtOAc:hexane=1:2) to give the colorless oil 17 (1.66 g, 99\%). $\mathrm{R}_{f} 0.22$ (EtOAc:hexane $=1: 3 ;{ }^{1} \mathrm{H}$ NMR $\left(300 \mathrm{MHz}, \mathrm{CDCl}_{3}\right) \delta 1.84$ (2H, m, propyl C2-H), $2.70(2 \mathrm{H}, \mathrm{t}, J=7.2 \mathrm{~Hz}$, propyl C1-H), $3.57(2 \mathrm{H}, \mathrm{t}, J=6.3 \mathrm{~Hz}$, propyl C3-H), $3.76(3 \mathrm{H}, \mathrm{s})$, $3.79(3 \mathrm{H}, \mathrm{s}), 6.67-6.79(3 \mathrm{H}, \mathrm{m}) ;{ }^{13} \mathrm{C} \mathrm{NMR}\left(75 \mathrm{MHz}, \mathrm{CDCl}_{3}\right) \delta 26.3$ (propyl C2), 33.3 (propyl $\mathrm{C} 1), 56.0\left(\mathrm{OCH}_{3}\right), 56.4\left(\mathrm{OCH}_{3}\right), 62.0\left(\mathrm{HOCH}_{2}\right), 111.3(\mathrm{C} 4), 111.5(\mathrm{C} 3), 116.6(\mathrm{C} 6), 131.3(\mathrm{C} 1)$, 151.8 (C2), 153.8 (C5); Anal. Calcd for $\mathrm{C}_{11} \mathrm{H}_{16} \mathrm{O}_{3}$ (196.24): C, 67.32; H, 8.22\% Found: C, 67.21, $\mathrm{H}, 8.13 \%$

1-(3-Benzyloxypropyl)-2,4-dimethoxybenzene (18). To a solution of $17(1.67 \mathrm{~g}, 8.49 \mathrm{mmol})$ in THF $(25 \mathrm{~mL})$ under a nitrogen atmosphere was added $\mathrm{NaH}(1.02 \mathrm{~g}, 25.5 \mathrm{mmol})$ with $\mathrm{BnBr}$ $(1.50 \mathrm{~mL}, 12.7 \mathrm{mmol})$ and the mixture heated at reflux for $10 \mathrm{~h}$. After the solution was filtered through Celite, the solvent was removed by evaporation and the residue was extracted with $\mathrm{CH}_{2} \mathrm{Cl}_{2}$, the extract washed with brine, dried and concentrated to give a crude oil, which was purified by chromatography (EtOAc:hexane $=1: 7)$ to give $\mathbf{1 8}$ as a colorless oil $(2.43 \mathrm{~g}, 99 \%) . \mathrm{R}_{f}$ 0.63 (EtOAc:hexane=1:3); ${ }^{1} \mathrm{H}$ NMR $\left(300 \mathrm{MHz}, \mathrm{CDCl}_{3}\right) \delta 1.91(2 \mathrm{H}, \mathrm{m}), 2.68(2 \mathrm{H}, \mathrm{t}, J=7.5 \mathrm{~Hz})$, $3.50(2 \mathrm{H}, \mathrm{t}, J=6.6 \mathrm{~Hz}), 3.74(3 \mathrm{H}, \mathrm{s}), 3.76(3 \mathrm{H}, \mathrm{s}), 4.51\left(2 \mathrm{H}, \mathrm{s}\right.$, benzyl- $\left.\mathrm{CH}_{2}\right), 6.65-6.76(3 \mathrm{H}, \mathrm{m})$, 7.24-7.34 (5H, m); ${ }^{13} \mathrm{C}$ NMR (75 MHz, $\mathrm{CDCl}_{3}$ ) $\delta 27.4$ (propyl C2), 30.1 (propyl C1), 56.0 $\left(\mathrm{OCH}_{3}\right), 56.2\left(\mathrm{OCH}_{3}\right), 70.3\left(\mathrm{OCH}_{2}\right), 73.1\left(\mathrm{OCH}_{2} \mathrm{Ph}\right), 111.1(\mathrm{C} 4), 111.3(\mathrm{C} 3), 116.5(\mathrm{C} 6), 127.7$ (benzyl C4), 127.8 (x2), 128.5 (x2), 131.8 (C1), 138.9 (benzyl C1), 152.0 (C2), 153.5 (C5); Anal. Calcd for $\mathrm{C}_{18} \mathrm{H}_{22} \mathrm{O}_{3}$ (286.37): C, 75.50; H, 7.74\% Found: C, 75.35, H, 7.62\%

1-(3-Benzyloxypropyl)-4-iodo-2,5-dimethoxybenzene (19). To a solution of $\mathbf{1 8}$ (4.44 g, $15.5 \mathrm{mmol})$ in EtOH $(150 \mathrm{~mL})$ under nitrogen atmosphere was added $\mathrm{I}_{2}(4.72 \mathrm{~g}, 18.6 \mathrm{mmol})$ with 
silver sulfate $(5.80 \mathrm{~g}, 18.6 \mathrm{mmol})$ and stirred for $2 \mathrm{~h}$ at $\mathrm{rt}$. Solvent was removed by evaporation and the residue was extracted into $\mathrm{CH}_{2} \mathrm{Cl}_{2}$, the extract washed with brine, dried and concentrated to give a solid. The solid was purified by chromatography (EtOAc:hexane=1:7) to give $\mathbf{1 9}$ as a white solid (6.18 g, 97\%). $\mathrm{R}_{f} 0.72$ (EtOAc:hexane=1:2); mp 52-54 ${ }^{\circ} \mathrm{C}$; ${ }^{1} \mathrm{H}$ NMR $(300 \mathrm{MHz}$, $\left.\mathrm{CDCl}_{3}\right) \delta 1.88(2 \mathrm{H}, \mathrm{m}), 2.67(2 \mathrm{H}, \mathrm{t}, J=7.5 \mathrm{~Hz}), 3.48(2 \mathrm{H}, \mathrm{t}, J=6.3 \mathrm{~Hz}), 3.74(3 \mathrm{H}, \mathrm{s}), 3.77(3 \mathrm{H}, \mathrm{s})$, $4.50(2 \mathrm{H}, \mathrm{s}), 6.64(1 \mathrm{H}, \mathrm{s}, \mathrm{C} 6-\mathrm{H}), 7.17(1 \mathrm{H}, \mathrm{s}, \mathrm{C} 3-\mathrm{H}), 7.23-7.34(5 \mathrm{H}, \mathrm{m}) ;{ }^{13} \mathrm{C} \mathrm{NMR}(75 \mathrm{MHz}$, $\left.\mathrm{CDCl}_{3}\right) \delta 27.7,30.0,56.4,57.4,70.1,73.2,82.1$ (C4-I), 113.6 (C3), 121.6 (C6), 127.7, 127.8 (x2), 128.6 (x2), 132.0 (C1), 138.8, 152.5 (x2); Anal. Calcd for $\mathrm{C}_{18} \mathrm{H}_{21} \mathrm{IO}_{3}$ (412.26): C, 52.44; $\mathrm{H}$, 5.13; I, 30.78\% Found: C, 52.28, H, 5.05; I, 30.75\%

\section{1-(4-Benzyloxy-3-methoxyphenyl)-2-[4-(3-benzyloxypropyl)-2,5-dimethoxyphenyl]acetylene} (20). To a solution of 19 (0.41 g, $1.00 \mathrm{mmol}), \mathrm{PdCl}_{2}\left(\mathrm{PPh}_{3}\right)_{2}(0.014 \mathrm{~g}, 0.02 \mathrm{mmol})$, 4-benzyloxy3-methoxyphenylacetylene (10, $0.36 \mathrm{~g}, 1.50 \mathrm{mmol})$ and $\mathrm{CuI}(0.005 \mathrm{~g}, 0.03 \mathrm{mmol})$ in $\mathrm{DMF}$ $(7 \mathrm{~mL})$ under nitrogen was added $\mathrm{Et}_{3} \mathrm{~N}(0.28 \mathrm{~mL}, 2.00 \mathrm{mmol})$ and stirred for $48 \mathrm{~h}$ at $\mathrm{rt}$. The reaction mixture was extracted with $\mathrm{CHCl}_{3}$, the extract washed with brine, dried and concentrated to give a solid which was purified by chromatography (EtOAc:hexane=1:3) to give 20 as a yellow solid (0.49 g, 93\%). $\mathrm{R}_{f} 0.40$ (EtOAc:hexane=1:3); mp 90-92 ${ }^{\circ} \mathrm{C} ;{ }^{1} \mathrm{H}$ NMR (300 $\left.\mathrm{MHz}, \mathrm{CDCl}_{3}\right) \delta 1.91(2 \mathrm{H}, \mathrm{m}), 2.71(2 \mathrm{H}, \mathrm{t}, J=8.4 \mathrm{~Hz}), 3.50(2 \mathrm{H}, \mathrm{t}, J=6.3 \mathrm{~Hz}), 3.78(3 \mathrm{H}, \mathrm{s}), 3.83$ $(3 \mathrm{H}, \mathrm{s}), 3.89(3 \mathrm{H}, \mathrm{s}), 4.51(2 \mathrm{H}, \mathrm{s}), 5.16(2 \mathrm{H}, \mathrm{s}), 6.70\left(1 \mathrm{H}, \mathrm{s}, \mathrm{C} 3{ }^{\prime}-\mathrm{H}\right), 6.82(1 \mathrm{H}, \mathrm{d}, J=8.7 \mathrm{~Hz}, \mathrm{C} 5-$ $\mathrm{H}), 6.93\left(1 \mathrm{H}, \mathrm{s}, \mathrm{C} 6{ }^{\prime}-\mathrm{H}\right), 7.05-7.09(2 \mathrm{H}, \mathrm{m}), 7.27-7.43(10 \mathrm{H}, \mathrm{m}) ;{ }^{13} \mathrm{C} \mathrm{NMR}\left(75 \mathrm{MHz}, \mathrm{CDCl}_{3}\right) \delta$ 27.8, 30.0, 56.2, 56.3, 56.8, 70.1, 71.2, 73.2, 84.8 (acetylene), 93.1 (acetylene), 113.7, 113.8, $115.1,115.2,116.5,125.0,127.5$ (x2), 127.7, 127.8 (x2), 128.1, 128.6 (x2), 128.7 (x2), 128.8, 132.6, 137.0, 138.8, 148.6, 149.3, 151.3, 154.2; Anal. Calcd for $\mathrm{C}_{34} \mathrm{H}_{34} \mathrm{O}_{5}$ (522.63): C, 78.14; $\mathrm{H}$, 6.56\% Found: C, 78.05, H, 6.39\%

2-(4-Benzyloxy-3-methoxyphenyl)-6-(3-benzyloxypropyl)-3-iodo-5-methoxybenzofuran (21). To a solution of $20(0.49 \mathrm{~g}, 0.93 \mathrm{mmol})$ in $\mathrm{CHCl}_{3}(20 \mathrm{~mL})$ was slowly added $\mathrm{I}_{2}(0.47 \mathrm{~g}$, $1.86 \mathrm{mmol}$ ) at $-20{ }^{\circ} \mathrm{C}$ and the mixture stirred for $5 \mathrm{~h}$ at $\mathrm{rt}$. After addition of aqueous $\mathrm{NaHCO}_{3}$, the mixture was extracted with $\mathrm{CHCl}_{3}$, washed with brine, dried and concentrated to give the solid. The solid was purified by chromatography (EtOAc:hexane=1:3) to give 21 as a yellow solid (0.48 g, 82\%). $\mathrm{R}_{f} 0.60$ (EtOAc:hexane=1:3); mp 82-84 ${ }^{\circ} \mathrm{C} ;{ }^{1} \mathrm{H}$ NMR $\left(300 \mathrm{MHz}, \mathrm{CDCl}_{3}\right) \delta 1.95$ $(2 \mathrm{H}, \mathrm{m}), 2.81(2 \mathrm{H}, \mathrm{t}, J=7.5 \mathrm{~Hz}), 3.51(2 \mathrm{H}, \mathrm{t}, J=6.3 \mathrm{~Hz}), 3.90(3 \mathrm{H}, \mathrm{s}), 3.99(3 \mathrm{H}, \mathrm{s}), 4.51(2 \mathrm{H}, \mathrm{s})$, $5.21(2 \mathrm{H}, \mathrm{s}), 6.76(1 \mathrm{H}, \mathrm{s}), 6.96(1 \mathrm{H}, \mathrm{d}, J=8.1 \mathrm{~Hz}, \mathrm{C} 4 \mathrm{\prime}-\mathrm{H}), 7.21(1 \mathrm{H}, \mathrm{s}), 7.23-7.39(8 \mathrm{H}, \mathrm{m}), 7.44$ $(1 \mathrm{H}, \mathrm{s}), 7.45(1 \mathrm{H}, \mathrm{d}, J=7.2 \mathrm{~Hz}, \mathrm{C} 5 '-\mathrm{H}), 7.65-7.70(2 \mathrm{H}, \mathrm{m}) ;{ }^{13} \mathrm{C} \mathrm{NMR}\left(75 \mathrm{MHz}, \mathrm{CDCl}_{3}\right) \delta 27.9$, $30.1,56.2,56.5,60.0,70.1,71.2,73.1,101.9,111.0,112.2,113.6,120.4,123.7,127.4$ (x2), $127.7,127.9$ (x2), 128.1, 128.5 (x2), 128.8 (x2), 129.7, 131.0, 137.0, 138.8, 148.3, 149.0, 149.5, 152.9, 155.0; Anal. Calcd for $\mathrm{C}_{33} \mathrm{H}_{31} \mathrm{IO}_{5}$ (634.50): C, 62.47; H, 4.92; I, 20.00\% Found: $\mathrm{C}, 62.25$, H, 4.75; I, 20.09\%

\section{2-(4-Benzyloxy-3-methoxyphenyl)-6-(3-benzyloxypropyl)-5-methoxybenzofuran-3-}

carbaldehyde (22). To a solution of $21(0.10 \mathrm{~g}, 0.16 \mathrm{mmol})$ in toluene $(7 \mathrm{~mL})$ under a nitrogen atmosphere was added $N$-formylpiperidine $(0.17 \mathrm{~mL}, 1.56 \mathrm{mmol})$ with $n$-BuLi $(0.92 \mathrm{~mL}, 1.6 \mathrm{M}$ in hexane) and the whole stirred for $1 \mathrm{~h}$ at $0{ }^{\circ} \mathrm{C}$. After the solution was neutralized with $1 \mathrm{~N} \mathrm{HCl}$, 
the organic product was extracted with diethyl ether, the extract washed with brine, dried and concentrated to give a solid which was purified by chromatography (EtOAc:hexane=1:4) to give 22 as a yellow solid (0.073 g, 87\%). $\mathrm{R}_{f} 0.41$ (EtOAc:hexane=1:3); mp 76-78 ${ }^{\circ} \mathrm{C} ;{ }^{1} \mathrm{H}$ NMR (300 $\left.\mathrm{MHz}, \mathrm{CDCl}_{3}\right) \delta 1.96(2 \mathrm{H}, \mathrm{m}), 2.82(2 \mathrm{H}, \mathrm{t}, J=7.5 \mathrm{~Hz}), 3.52(2 \mathrm{H}, \mathrm{t}, J=6.3 \mathrm{~Hz}), 3.90(3 \mathrm{H}, \mathrm{s}), 3.99$ $(3 \mathrm{H}, \mathrm{s}), 4.52(2 \mathrm{H}, \mathrm{s}), 5.25(2 \mathrm{H}, \mathrm{s}), 7.01(1 \mathrm{H}, \mathrm{d}, J=8.4 \mathrm{~Hz}, \mathrm{C} 5 '-\mathrm{H}), 7.24-7.47(13 \mathrm{H}, \mathrm{m}), 7.64(1 \mathrm{H}$, $\mathrm{s}, \mathrm{C} 7-\mathrm{H}), 10.27(1 \mathrm{H}, \mathrm{s}, \mathrm{CHO}) ;{ }^{13} \mathrm{C} \mathrm{NMR}\left(75 \mathrm{MHz}, \mathrm{CDCl}_{3}\right) \delta 28.0,30.0,56.2,56.6,70.1,71.2$, $73.1,102.7,111.8,112.0,113.8,117.3,122.0,122.7,124.1,127.4(x 2), 127.7,127.9(x 2), 128.3$, 128.5 (x2), 128.9 (x2), 130.0, 136.5, 138.8, 148.6, 150.1, 150.8, 155.8, 165.4, 186.9 (CHO); Anal. Calcd for $\mathrm{C}_{34} \mathrm{H}_{32} \mathrm{O}_{6}$ (536.61): C, 76.10; H, 6.01\% Found: C, 75.93, H, 5.97\%

\section{2-(4-Hydroxy-3-methoxyphenyl)-6-(3-hydroxypropyl)-5-methoxybenzofuran-3-}

carbaldehyde (3). To a solution of $22(0.02 \mathrm{~g}, 0.04 \mathrm{mmol})$ in $\mathrm{CH}_{2} \mathrm{Cl}_{2}(5 \mathrm{~mL})$ was added $\mathrm{BBr}_{3}$ $\left(0.07 \mathrm{~mL}, 1.0 \mathrm{M}\right.$ in $\mathrm{CH}_{2} \mathrm{Cl}_{2}$ ) and the reaction mixture stirred for $1 \mathrm{~h}$ at $-78{ }^{\circ} \mathrm{C}$. The mixture was extracted with $\mathrm{CH}_{2} \mathrm{Cl}_{2}$, the extract washed with brine, dried and concentrated to give a solid which was purified by chromatography $\left(\mathrm{MeOH}: \mathrm{CHCl}_{3}=1: 15\right)$ to give 3 as a yellow solid $(0.012 \mathrm{~g}$, 92\%). $\mathrm{R}_{f} 0.54\left(\mathrm{MeOH}: \mathrm{CHCl}_{3}=1: 15\right)$; mp 134-136 ${ }^{\circ} \mathrm{C} ;{ }^{1} \mathrm{H} \mathrm{NMR}\left(300 \mathrm{MHz}, \mathrm{CD}_{3} \mathrm{OD}\right) \delta(2 \mathrm{H}, \mathrm{m}$, propyl C2-H), $2.76\left(2 \mathrm{H}, \mathrm{t}, J=7.8 \mathrm{~Hz}\right.$, propyl C1-H), $3.58\left(2 \mathrm{H}, \mathrm{t}, J=6.6 \mathrm{~Hz}, \mathrm{CH}_{2} \mathrm{OH}\right), 3.87(3 \mathrm{H}, \mathrm{s}$, C3'-OCH $\left.{ }^{\prime}\right), 3.95\left(3 \mathrm{H}, \mathrm{s}, \mathrm{C} 5-\mathrm{OCH}_{3}\right), 6.95(1 \mathrm{H}, \mathrm{d}, J=8.4 \mathrm{~Hz}, \mathrm{C} 5$ ' $-\mathrm{H}), 7.32(1 \mathrm{H}, \mathrm{s}, \mathrm{C} 4-\mathrm{H}), 7.38$ (1H, dd. J=1.8, 15.6 Hz, C6'-H), 7.40 (1H, br s, C2'-H), 7.58 (1H, s, C7-H), 10.18 (1H, s, CHO); ${ }^{13} \mathrm{C}$ NMR (75 MHz, DMSO-d 6 ) $\delta 27.5$ (propyl C2), 33.3 (propyl C1), $56.5\left(\mathrm{C}^{\prime}-\mathrm{OCH}_{3}\right), 56.6$ $\left(\mathrm{C}^{2}-\mathrm{OCH}_{3}\right), 61.1\left(\mathrm{CH}_{2} \mathrm{OH}\right), 102.5(\mathrm{C} 4), 112.4\left(\mathrm{C}^{\prime}\right.$ '), 112.9 (C5'), 116.3 (C6), 116.7 (C7), 119.8 (C6'), 123.4 (C3a), 124.2 (C1'), 130.0 (C3), 148.2 (C4'), 148.7 (C3'), 150.5 (C5), 155.6 (C7a), 165.6 (C2), 187.3 (CHO). Anal. Calcd for $\mathrm{C}_{20} \mathrm{H}_{20} \mathrm{O}_{6}$ (356.37): C, 67.41; H, 5.66\%. Found: C, $67.13 ; \mathrm{H}, 5.55 \%$.

\section{Acknowledgements}

This work was supported by a Korea Research Foundation Grant funded by the Korean Government (MOEHRD, Basic Research Promotion Fund) (KRF-2007-412-J00501).

\section{References}

1. Chang, H. M.; Cheng, K. P.; Choang, T. F.; Chow, H. F.; Chui, K. Y.; Hon, P. M.; Tan, F. W. L.; Yang, Y.; Zhong, Z. P.; Lee, C. M.; Sham, H. L.; Chan, C. F.; Cui, Y. X.; Wong, H. N. C. J. Org. Chem. 1990, 55, 3537.

2. Cheung, W. T.; Shi, M.-M.; Young, J. D.; Lee, C. M. Biochem. Pharmacol. 1987, 36, 2183.

3. Yang, Z.; Hon, P. M.; Chui, K. Y.; Xu, Z. L.; Chang, H. M.; Lee, C. M.; Cui, Y. X.; Wong, H. N. C.; Poon, C. D.; Fung, B. M. Tetrahedron Lett. 1991, 32, 2061.

4. (a) Dean, F. M. The Total Synthesis of Natural Products; ApSimon, J., Ed.; Wiley: New 
York, 1973; Vol. 1, pp 467-562. (b) Comprehensive Heterocyclic Chemistry II; Katritzky, A. R., Rees, C. W., Scriven, E. F. V., Eds.; Pergamon Press: Oxford, UK, 1996; Vol. 2, pp 259321. (c) Park, S. Y.; Lee, H.-J.; Lee, O.-K.; Kang, H.-Y.; Choi, D.-H.; Paik, K.-H.; Khan, M. Bull. Korean Chem. Soc. 2007, 28, 1874.

5. (a) Yang, Z.; Liu, H. B.; Lee, C. M.; Chang, H. M.; Wong, H. N. C. J. Org. Chem. 1992, 57, 7248. (b) Kuo, Y.-H.; Wu, C.-H. J. Nat. Prod. 1996, 59, 625. (c) Luetjens, H.; Scammells, P. J. Tetrahedron Lett. 1998, 39, 6581. (d) Hutchinson, S. A.; Luetjens, H.; Scammells, P. J. Bioorg. Med. Chem. Lett. 1997, 7, 3081. (e) Kao, C.-L.; Chern, J.-W. J. Org. Chem. 2002, 67, 6772. (f) Bang, H. B.; Han S. Y.; Choi, D. H.; Yang D. M.; Hwang, J. W.; Lee, H. S.; Jun, J.-G. Synth. Commun. 2009, 39, 506.

6. Jacobson, K. A.; van Galen, P. J. M.; Williams, M. J. Med. Chem. 1992, 35, 407.

7. (a) Yue, D.; Yao, T.; Larock, R. C. J. Org. Chem. 2005, 70, 10292. (b) Hathaway, B. A.; White, K. L.; McGill, M. E. Synth. Commun. 2007, 37, 3855.

8. Leadbeater, N. E.; Tominack, B. J. Tetrahedron Lett. 2003, 44, 8653.

9. Colvin, E. W.; Hamill, B. J. J. Chem. Soc., Perkin Trans. 1 1977, 869.

10. (a) Sonogashira, K. J. Organomet. Chem. 2002, 653, 46. (b) Choi, D. H.; Hwang, J. W.; Lee, H. S.; Yang D. M.; Jun, J.-G. Bull. Korean Chem. Soc. 2008, 29, 1594. 